\title{
Animal Models of Bacterial Keratitis
}

\author{
Mary E. Marquart \\ Department of Microbiology, University of Mississippi Medical Center, 2500 North State Street, Jackson, MS 39216, USA \\ Correspondence should be addressed to Mary E. Marquart, mmarquart@umc.edu
}

Received 16 October 2010; Revised 29 November 2010; Accepted 9 December 2010

Academic Editor: Oreste Gualillo

Copyright (C) 2011 Mary E. Marquart. This is an open access article distributed under the Creative Commons Attribution License, which permits unrestricted use, distribution, and reproduction in any medium, provided the original work is properly cited.

Bacterial keratitis is a disease of the cornea characterized by pain, redness, inflammation, and opacity. Common causes of this disease are Pseudomonas aeruginosa and Staphylococcus aureus. Animal models of keratitis have been used to elucidate both the bacterial factors and the host inflammatory response involved in the disease. Reviewed herein are animal models of bacterial keratitis and some of the key findings in the last several decades.

\section{Introduction}

The human eye is composed of mucosal surfaces, such as the mucosal epithelium of the cornea, as well as interior chambers, such as the vitreous humor, that are potential targets of infection (Figure 1). Bacterial infections of the eye can range from mild, self-limiting conjunctivitis to devastating panophthalmitis involving the entire orbit. Infectious diseases of the eye not only involve the effects of bacterial colonization and virulence factors but also the host responses to the pathogen. This interplay between bacterium and host often necessitates the use of live animal models for the study of ocular infections and development of efficacious treatments.

Keratitis, a disease of the cornea, can result from direct infection with viruses, bacteria, fungi, yeast, and amoebae or from immune-related complications such as the sterile keratitis associated with Lyme disease. Bacterial keratitis can occur in a variety of mammals and can be caused by multitudes of bacterial species. The most common species that have been associated with bacterial keratitis in humans in the United States in the last 50 years or so are Pseudomonas aeruginosa (Figure 2) and Staphylococcus aureus (Figure 3). Many of the epidemiological reports from India implicate Streptococcus pneumoniae as the most frequent cause. The differences observed in bacterial causes of keratitis in different regions and countries have sparked an interest in climate as a possible factor in the disease.

Many manuscripts published in the first half of the twentieth century were studies of trachoma, an ocular infection caused by Chlamydia trachomatis characterized by conjunctivitis, swollen eyelids, and sometimes corneal haze [1-4]. Other early studies of note were focused on neonatal conjunctivitis and its treatment [5-7] as well as gonococcal and tuberculous eye infections $[7,8]$. The majority of reports at that time were observational studies of clinical cases and outcomes following treatment with penicillin, sulphonamides, or newer antibiotics such as tetracyclines and macrolides [1-3, 5, 9-14]. Since that time, studies of ocular bacterial infections expanded to address the mechanisms of pathogenesis and the inflammatory response in a so-called "immune-privileged" site. Basic and clinical researches leading to newer treatments and the development of newer surgical techniques have allowed for decreases in the incidence of some infections [15-17].

\section{Rabbits and Pseudomonas aeruginosa}

The most commonly used strain of rabbits for bacterial keratitis studies is the New Zealand White rabbit, although Dutch-belted rabbits have also been used. One of the earlier techniques of inducing Pseudomonas keratitis in the rabbit was developed by Hessburg and coworkers [19], in which a silk suture contaminated with the bacteria was passed through the rabbit corneal stroma. This technique was later used in the examination of Pseudomonas proteases that had been known to cause massive destruction of the cornea [20], and for antibiotic efficacy against $P$. aeruginosa [21]. Kessler et al. [22] used the intrastromal injection model, in 


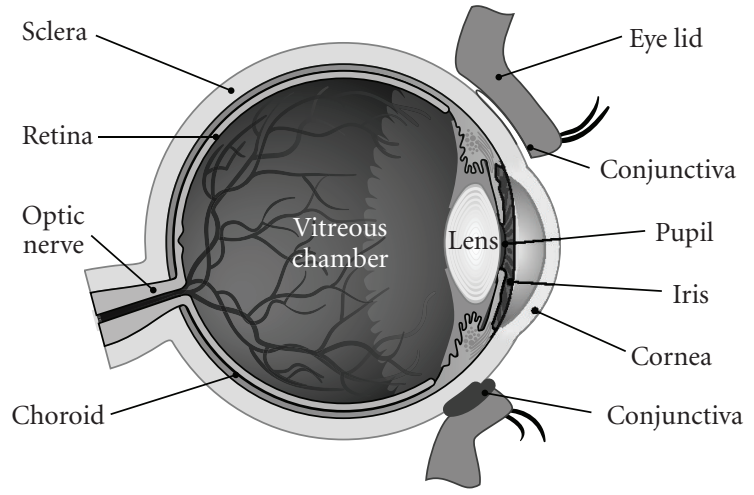

Figure 1: Diagram of the human eye (illustration by Michael K. Krider).

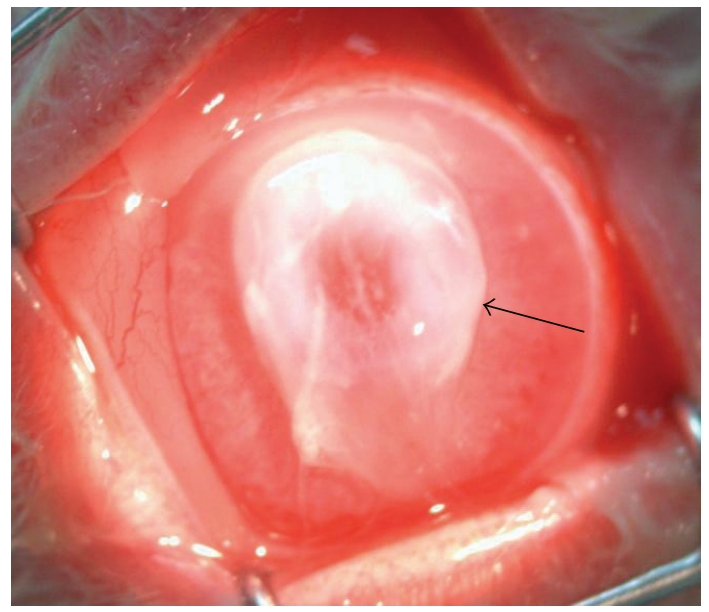

Figure 2: Pseudomonas keratitis in the New Zealand white rabbit 25 hours after infection. Experimental keratitis was induced by intracorneal injection of 1000 colony-forming units of a clinical urine isolate of $P$. aeruginosa according to the method of O'Callaghan's group [18]. The arrow indicates the edge of a purulent corneal ulcer.

which bacteria were injected directly within the cornea, to test the proteolytic activity of heat-killed $P$. aeruginosa in the rabbit cornea, and to examine the host response to the heat-killed bacteria. They suggested not only that the host produced a massive influx of polymorphonuclear leukocytes (PMNs) in response to the injection but also that the corneal damage could be due to host-produced proteolytic enzymes, now known to be host matrix metalloproteinases (MMPs). The influx of inflammatory cells has also been implicated as a cause of host corneal disease severity in Pseudomonas keratitis in the rabbit [23].

Numerous investigations using the rabbit cornea as a model for studying Pseudomonas virulence factors have since been published. For example, Iglewski et al. [24] injected purified exotoxin A into corneas and observed toxic effects which were neutralized by antitoxin. Thibodeaux et al. [25] transformed the genes for two $P$. aeruginosa virulence factors, elastase and alkaline protease, into a species deemed nonpathogenic in the rabbit eye, Pseudomonas putida. Since

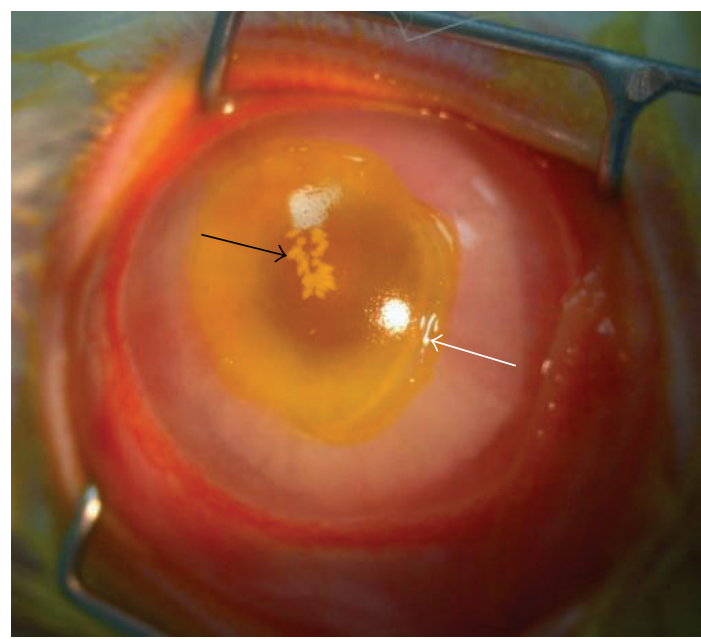

Figure 3: Staphylococcus keratitis in the New Zealand white rabbit 19 hours after infection. Experimental keratitis was induced by intracorneal injection of 100 colony-forming units of methicillinresistant $S$. aureus (clinical blood specimen) according to the method of O'Callaghan's group [18]. The black arrow indicates the presence of stromal infiltration, and the white arrow indicates the edge of a large corneal epithelial erosion, which was stained with fluorescein for ease of visualization.

$P$. aeruginosa had been determined to increase production of other proteases when a particular protease was deleted, examining the role of a particular protease in keratitis by genetic deletion was complicated. Transformation and expression of single proteases into a nonpathogenic host such as $P$. putida allowed the investigators to determine that elastase was important for the production of corneal erosions during $P$. aeruginosa keratitis [25].

Various antibiotics and novel therapies have been tested against Pseudomonas in the rabbit using the intrastromal method of inoculation $[18,26-41]$ as well as topical inoculation [42]. Other modes of inoculation to produce keratitis by $P$. aeruginosa include topical inoculation preceded by corneal scratch [43-45], corneal abrasion [46], and mechanical removal of the corneal epithelium [42]. Pseudomonascontaminated contact lenses have also been used in rabbits [47-51].

Besides antibiotic studies, rabbits have been used in a variety of immunization studies to determine whether vaccination against particular bacteria or bacterial antigens could provide protection against keratitis. Kreger et al. [52] immunized rabbits against $P$. aeruginosa lipopolysaccharide or purified proteases and then challenged their corneas with bacteria. The immunizations provided protection against the severity of Pseudomonas keratitis.

A corneal flap model has also been developed for $P$. aeruginosa to mimic surgical complications, such as keratitis after laser-assisted in situ keratomileusis (LASIK). Holzer et al. used Dutch-belted rabbits for several studies of diffuse lamellar keratitis following corneal flap surgery [5356]. These studies entailed creating a corneal flap in the rabbit eye, applying $P$. aeruginosa lipopolysaccharide to the 
area, and then examining the eye for inflammation both in vivo and by histopathology.

\section{Rabbits and Staphylococcus aureus}

S. aureus keratitis has not been reported to be achieved by topical inoculation of the rabbit cornea without additional manipulations such as the application of bacteria-soaked contact lenses; therefore, the usual method to achieve Staphylococcus keratitis is intracorneal injection. One of the older $S$. aureus studies was an antibiotic efficacy study with intracorneal injections of bacteria and application of topical antibiotic ointments to the eyes [57]. Kupferman and Leibowitz [58] reported the intrastromal injection model of keratitis in rabbits and showed this model to be highly reproducible. These authors later used this model to test the efficacy of topical antibiotic therapy of S. aureus keratitis [59] and found that in vitro minimal inhibitory concentration assays of the antibiotics they tested did not necessarily reflect efficacies of these drugs in the eye. Moreover, they cautioned that not all strains of $S$. aureus would necessarily have the same sensitivities as the strain used in their study. Their findings continue to be relevant to date.

The rabbit model of $S$. aureus keratitis is continually used to study antimicrobial and/or antipathological compounds $[18,30,32-34,36,40,41,60-83]$ as well as host factors involved in the disease [84-87]. One of the most significant findings regarding $S$. aureus keratitis using the rabbit intracorneal model was that alpha-toxin was the major bacterial virulence factor responsible for disease severity [88-91]. Moreover, immunization against alpha-toxin was protective against S. aureus keratitis [92], and treatment of infected corneas with cholesterol conjugated to cyclodextrin as a means to inhibit alpha-toxin was able to significantly decrease disease severity [80].

Alternatives to the intrastromal model include soaking contact lenses in S. aureus prior to placement on wounded rabbit corneas [84, 93-95] and induction of a post-LASIK model of keratitis in which $S$. aureus was inoculated underneath rabbit corneal flaps that mimic LASIK surgery [96] and other corneal flap models [97-99].

\section{Mice and Pseudomonas aeruginosa}

The advantage of the rabbit as a model for bacterial keratitis is that its eyes are large like human eyes so several disease parameters can be assessed. One such scale involves the scoring of seven parameters such that a maximum disease score would be 28 [100]. Mice have smaller eyes and are often assigned disease scores up to a maximum of 4 [101] because of fewer parameters that are able to be assessed. For example, conjunctival redness and the presence of fibrin in the anterior chamber can be visualized in the rabbit. However, mice have other advantages as models for bacterial keratitis. There are numerous strains of inbred and outbred mice, a multitude of commercially available reagents with which to analyze mouse-specific factors, and the availability of genetically modified mice.
Gerke and Magliocco [102] first reported using the mouse as a model for Pseudomonas aeruginosa keratitis. They used different methods of corneal wounding prior to topical inoculation to achieve infection: incision (3 deep scratches that did not penetrate into the anterior chamber), a $2 \mathrm{~mm}$ surface scratch, and needle puncture. They also performed direct intrastromal injection of bacteria and determined that the incision and injection modes were most consistent with respect to pathology. To date, the majority of mouse corneal inoculations with $P$. aeruginosa have been by topical scratch of the cornea followed by dropping the bacteria onto the eye.

Mice have been used for immunization studies for the possible development of alternative prophylaxes and therapies of $P$. aeruginosa keratitis. In one such study, mice were immunized with whole $P$. aeruginosa cells by intraperitoneal or oral route, and their corneas were subsequently challenged [103]. Monovalent and multivalent vaccines were used, and it was found that intraperitoneal immunization with the multivalent vaccine worked the best. These authors pointed to another report that was published in 1927 that tested Pseudomonas keratitis in vivo and alluded to the potential for protection against keratitis by vaccination [104].

Immunizations of mice with Pseudomonas aeruginosa protease and elastase toxoids, as well as the common Oantigen, were able to protect against keratitis $[105,106]$. Moreover, passive administration of rabbit antisera to mice $[52,106]$, or passive immunization of mice with monoclonal antibodies specific for Pseudomonas outer membrane proteins [107], was able to successfully treat Pseudomonas keratitis. Zaidi et al. [108] demonstrated protection against Pseudomonas keratitis by active and passive immunization of live attenuated bacteria in $\mathrm{C} 3 \mathrm{H} / \mathrm{HeN}$ mice.

Mice have also been used in therapy efficacy studies of antibiotics and other potential antimicrobial compounds $[109,110]$. Hobden's group recently showed that nona-Darginine amide was bactericidal to $P$. aeruginosa and exerted anti-inflammatory effects in the infected mouse cornea [111, 112]. Kumar et al. [113] applied flagellin, a bacterial flagellar protein and an agonist of toll-like receptor 5 (TLR5), to the corneas of B6 mice and found that it protected the corneas from severity of disease and bacterial loads. Human tear fluid has also been found to protect against Pseudomonas keratitis in C57/BL6 mice [114]. Other novel therapies of interest using this model are caspase-1 inhibitor [115], silencing RNA molecules [116, 117], interleukin-6 (IL-6) [118], Spantide 1 [119], chemokine antibodies [120], cyclodextrin [121], and topical drops of alginate antibody [122].

Other studies of note involving Pseudomonas in the mouse model of keratitis include findings regarding the invasive potential of $P$. aeruginosa. Fleiszig et al. [123] first demonstrated that some strains of Pseudomonas were able to invade mouse corneal cells in vivo and subsequently showed that $P$. aeruginosa multiplied within the cells [124]. Invasive strains were found to produce type III secreted exoproteins that enabled internalization of the bacteria into mouse corneal epithelial cells [125]. Fleiszig's group has also examined alternative methods of corneal infection in the mouse. One such method involved a modification of the topical scratch in which the epithelium was allowed to 
partially heal after the scratch before inoculation with $P$. aeruginosa [126]. In contrast to the invasive strains, cytotoxic strains have been shown to secrete several proteases that damage corneal tissue or induce the host immune response in the mouse model [127-130].

Prior to the development and use of transgenic animal models, studies on the host involvement in keratitis were often focused on the differences between mouse strains, elderly versus young mice, or drug-induced alterations in animals. Hazlett et al. [131] showed that administration of cyclophosphamide to mice caused Pseudomonas corneal infection to spread and become systemic, confirming previous suspicions that immunocompromised cancer patients were at a higher risk for systemic infection following Pseudomonas ocular infections. This same research group also examined the differences in pathogenicity of Pseudomonas keratitis in a strain of mouse that was determined to be "susceptible" to corneal infection (C57BL/6J, or T helper cell type 1 responder) and a strain determined to be "resistant" to corneal infection (DBA/2J) [132]. The susceptible strain was shown to have a decreased immune response to the bacteria as measured by a reduction in inflammatory cells compared to the resistant strain. Aged outbred mice with decreased PMN response to corneal infection with $P$. aeruginosa were also suggested to be less able to have restored corneal clarity than their young counterparts due to delayed bacterial clearance $[133,134]$. However, the presence of inflammatory cells has also been implicated as a cause of host corneal disease severity in Pseudomonas keratitis in the mouse [135-137]. These studies of general inflammatory responses to Pseudomonas keratitis, plus numerous others including analyses of cytokine expression, host MMP expression, and T-cell-mediated immune responses, have been followed by many studies with other species of bacteria as well as other strains of mice.

\section{Mice and Staphylococcus aureus}

O'Callaghan's group was the first to report a mouse model of S. aureus keratitis and showed that, similar to Pseudomonas keratitis, certain strains of mice were susceptible (BALB/c and $\mathrm{A} / \mathrm{J}$ ) to infection whereas others were resistant (C57BL/6) [138]. These investigators also showed that aged mice, like humans, were more susceptible to severe keratitis by $S$. aureus than young mice [139], and that S. aureus alphatoxin was responsible for much of the damage observed in the disease [140]. Other researchers have made slight modifications to the mouse model, such as breaking up the tear film prior to inoculation [141], or using a trephine for corneal scarification and inoculating with dead bacteria to observe inflammation [142].

\section{Genetically Modified Mice}

The advent of genetic modification of rodents has been revolutionary in examinations of the role of the host in bacterial keratitis. Mice in which specific genes have been deleted, altered, or alternatively controlled have been used in infection models to determine the host factors involved in disease. Most of the studies to date have used mice deficient in cytokines and other immune factors, such as toll-like receptors (TLRs). TLRs are present on or in host cells such as macrophages and epithelial cells and respond to pathogen-associated molecular patterns (PAMPs), triggering a signaling cascade that ultimately results in up- or downregulation of inflammatory molecules such as cytokines.

Pseudomonas keratitis studies using genetically modified mice have yielded information regarding the host response to this bacterium. Cole et al. [143] used interleukin-10 (IL-10) deficient mice to show that IL-10 was important in controlling inflammation in the cornea in response to $P$. aeruginosa. This group also used interleukin-4 (IL-4) deficient mice [144] and interleukin-6 (IL-6) deficient mice [145] to show a similar effect for IL-4 and IL-6 in S. aureus keratitis. Another study by Willcox and colleagues with mice lacking the gene for CXC chemokine receptor 2 showed that the host CXC chemokine receptor 2 was crucial for infiltration of PMNs into the eye and subsequent bacterial killing [146].

Genetic knockouts other than specific cytokines and chemokines have been investigated. Huang showed the importance of TLR4 in host resistance to Pseudomonas [147]. Likewise, mice deficient in MyD88, a TLR signaling molecule, had reduced immune cell recruitment to the eye in response to $P$. aeruginosa but had higher bacterial burden and developed systemic infections [148]. Hazlett's group used caspase-1 deficient mice to show that caspase1 was important for the inflammation observed during keratitis [149] and matrix metalloproteinase-9 (MMP-9) deficient mice to show that MMP-9 assists Pseudomonas keratitis by degrading corneal collagen and upregulating proinflammatory cytokines [150]. These investigators also recently showed a role for Fas ligand in the disease [151].

Recently, Pearlman's group [152] found that corneal macrophages were the predominant cell type in the cornea that expressed three TLRs of interest. The overall finding of the study was that activation of specific TLRs in the cornea by $P$. aeruginosa resulted in transcription of chemokines responsible for neutrophil recruitment to the cornea, and that this recruitment was responsible for both the inflammatory damage observed in the eye as well as the killing of the infecting bacteria. Likewise, macrophage migration inhibitory factor (MIF), when deleted from the mouse genome, results in a severe inflammatory response to Pseudomonas in the cornea [153]. Peptidoglycan recognition proteins, which are similar to TLRs in that they recognize PAMPs, have also been found to be important for innate immunity to Pseudomonas keratitis [154]. A role for host defensins has also been addressed for $P$. aeruginosa keratitis using cathelicidin deficient mice [155].

\section{Other Animals}

In 1975, Davis and Chandler reported an improved method of examining and quantitating Pseudomonas keratitis using the guinea pig as a model [156]. One of the foci of this report 
was the use of intracorneal injection of bacteria so that the inoculum would be as precise as possible. These investigators also used a scoring system for the disease severity and were able to quantitate the bacterial load from the corneas by plating dilutions of infected homogenized corneas onto bacterial growth medium. This method was determined to be highly reproducible and has since been used by numerous investigators, whether in guinea pigs or other animals such as rabbits. Davis and colleagues also used the guinea pig model for S. aureus keratitis [157].

Guinea pigs have also been used to study the role of antibacterial or anti-inflammatory agents in Pseudomonas keratitis [158-160] and contact-lens-related keratitis caused by $P$. aeruginosa [161]. Contact lenses were contaminated with the bacteria and then worn by guinea pigs for up to 48 hours to simulate extended contact lens wear by humans. The animals developed keratitis, or in some cases, a condition called contact-lens-induced acute red eye (CLARE) [161]. This research group has also used the guinea pig contact lens model to analyze the protective effect of melimine coating of contact lenses against $S$. aureus and P. aeruginosa [95]. A similar method to examine $P$. aeruginosa contamination of contact lenses designed for orthokeratology was reported using cats [162].

Rats have also been used in bacterial keratitis studies, and it is not apparent whether the strain of rat is important because different strains were successfully used for different reports. The method of topical corneal scratch and inoculation showed that the rat lacrimal gland responds to Pseudomonas corneal infection [163]. The intrastromal injection model has been used with rats to test whether amniotic membrane transplantation could aid in corneal healing following infection with S. aureus, and this technique was found to be useful as adjunct therapy to antibiotics [164]. Another infection model for rats has been the infection by the wearing of contaminated contact lenses [165]. A recent investigation determined that rats developed Pseudomonas keratitis after wearing contaminated contact lenses, and that transfer of the lenses to naïve rats caused transfer of the disease [166]. Other studies include antibiotic efficacy studies [167-169] and analysis of vitamin A deficiency and the corresponding susceptibility to Pseudomonas keratitis [170].

Mammals other than humans, in addition to being used as models, are potential victims of bacterial keratitis. For example, infectious bovine keratoconjunctivitis, usually caused by Moraxella bovis, is a major health problem in cattle. Pseudomonas, to name one genus, is a cause of keratitis in horses and dogs. Cats can also acquire bacterial keratitis, although less frequently than dogs. Numerous other mammals can develop keratitis, underscoring the prevalence of bacteria able to cause pathogenesis in the eye.

\section{Limitations of Animal Models}

Animals, particularly rabbits and mice, have been demonstrated to be useful models for studying bacterial keratitis. Some disadvantages exist, however, when using species that have characteristics different from humans. One of the most obvious differences is that most of the animals used as models are inbred. The advantage of using inbred animals is experimental consistency; however, inbred animals do not represent the human population as well as outbred animals. Less obvious differences are specific anatomical features, tissue composition, and various functions of ocular components in animals and humans. Humans have a corneal size of approximately $11 \mathrm{~mm}$ in diameter, whereas rabbits and mice have corneal sizes of about 13 and $2.2-3.5 \mathrm{~mm}$, respectively $[171,172]$. Corneal thickness is greater for humans than rabbits and mice, and the blink interval for humans is approximately 2.8 seconds whereas the interval for rabbits and mice is over 30 seconds [171]. Rabbits have a nictitating membrane whereas humans and mice do not. The arrangement of corneal collagen [171] and the properties of corneal epithelial cells [173] are different between rabbits, mice, and humans, which could produce alternate reactions of the cornea to invading pathogens. Likewise, the corneal epithelial basement membrane in humans is a network of fibers resembling a bird's nest, whereas that of the rabbit's is straight and flat. The anterior, collagen-rich banded portion of Descemet's membrane, which is the basement membrane of the corneal endothelium, appears organized in a pattern in humans but disorganized in rabbits [174]. Descemet's and Bowman's membranes are also substantially thinner in rabbits and mice than in humans [175]. Mouse corneas have a higher ratio of corneal epithelial cells to stroma than humans and more cell layers in the corneal epithelium [172]. Recently, confocal microscopy has detected more differences between species, such as subcellular differences between keratocytes of rabbits and mice [176]. Corneal proteins are also differentially present; for example, mice have abundant amounts of actin in their corneal epithelial cells whereas rabbits and humans do not [173]. All of these anatomical differences, as well as the blink intervals, have an effect on bacterial adherence and possible invasion, susceptibility to bacterial enzymes and other virulence factors, and availability of host defense molecules in the tear film.

Features outside of the cornea can account for discrepancies between the way humans and animals respond to ocular bacterial infections. The lacrimal gland, which is involved in tear secretion, is different for humans, rabbits, and rodents [177]. Compounding this difference is the vast gap in blink intervals between humans, rabbits, and mice as described above [171]. Not only is the architecture of the lacrimal gland different between these species, but also is function. For example, lysozyme is a paramount protein produced by the human lacrimal gland but is not as pronounced in rabbits and mice. This difference is important to note because lysozyme is an enzyme that damages bacterial cells walls. Other differences in lacrimal gland functions are electrolyte secretion, production of lipid-binding proteins, secretory IgA and secretory component secretion, and cytokine and growth factor secretion [177]. Many ocular surface mucins in humans terminate in sialic acids whereas those from rabbits terminate in 1-2 fucose or alpha-1-3 N-acetylgalactosamine [178]. Since bacteria produce enzymes which cleave specific residues in the host, studies of the effects of bacterial 
virulence in animals could yield results that necessitate cautious interpretation.

\section{Conclusion}

Infection of the cornea with bacterial pathogens such as $P$. aeruginosa and $S$. aureus can result in loss of vision due to the damage caused by the disease. This damage is attributed not only to bacterial factors but also to host immune factors. Therefore, models of bacterial keratitis have been developed in animals to analyze the disease from both the bacterial aspect and the host aspect. Despite the differences between human and animal characteristic that are involved in bacterial keratitis, the use of animal models has contributed to the understanding of this disease and the discovery of more effective treatments that may prevent corneal damage.

\section{Acknowledgment}

The author would like to thank Michael K. Krider for illustration of Figure 1 and Stephen Stray for proofreading the text.

\section{References}

[1] P. Thygeson, "The treatment of trachoma with sulfanilamide: a report of 28 cases," American Journal of Ophthalmology, vol. 37, pp. 395-403, 1939.

[2] M. J. Freyche, "Antibiotics and sulfonamides in the treatment of trachoma," Bulletin of the World Health Organization, vol. 2, no. 4, pp. 523-544, 1950.

[3] L. de Andrade, "Trachoma; diagnosis and treatment," The British Journal of Ophthalmology, vol. 35, no. 10, pp. 601-606, 1951.

[4] S. K. Allen and R. D. Semba, "The trachoma "menace" in the United States, 1897-1960," Survey of Ophthalmology, vol. 47, no. 5, pp. 500-509, 2002.

[5] A. Sorsby and I. Kane, "Optimal methods in the treatment of ophthalmia neonatorum," British Medical Journal, vol. 2, no. 4627, pp. 562-565, 1949.

[6] H. L. Ormsby, “Ophthalmia neonatorum," Canadian Medical Association Journal, vol. 72, no. 8, pp. 576-580, 1955.

[7] C. A. Smith and L. Halse, "Ophthalmia neonatorum," Public Health Reports, vol. 70, no. 5, pp. 462-470, 1955.

[8] D. P. Choyce and A. G. Cross, "An eye sanatorium; survey of one years' work," The British Journal of Ophthalmology, vol. 37, no. 7, pp. 405-414, 1953.

[9] L. P. Agarwal and B. M. Gupta, "Sulphonamides and antibiotic drugs in the treatment of trachoma," The British Journal of Ophthalmology, vol. 38, no. 2, pp. 119-122, 1954.

[10] R. R. Button, "Treatment of trachoma with erythromycin. A preliminary report of 21 cases," American Journal of Ophthalmology, vol. 39, no. 2, pp. 223-227, 1955.

[11] Y. Mitsui, K. Yamashita, and J. Hanabusa, "Treatment of trachoma with tetracycline," Antibiotic Medicine and Clinical Therapy, vol. 1, no. 4, pp. 225-226, 1955.

[12] H. Rais, "First attempts at treatment of trachoma with erythromycin.Premiers essais de traitement du trachome par l'éythromycine," Revue Internationale du Trachome, vol. 32, no. 4, pp. 459-462, 1955.
[13] P. J. Kozinn, A. Minsky, and E. Solomons, "Oxytetracycline ophthalmic solution in the prophylaxis of ophthalmia neonatorum," Antibiotics Annual, vol. 3, pp. 307-312, 1955.

[14] Y. Mitsui and K. Yamashita, "Tetracycline and tetracyclinehydrocortisone oil suspensions in trachoma," Antibiotics Annual, vol. 3, pp. 324-330, 1955.

[15] M. L. Durand and C. H. Dohlman, "Successful prevention of bacterial endophthalmitis in eyes with the boston keratoprosthesis," Cornea, vol. 28, no. 8, pp. 896-901, 2009.

[16] J. Suzuki, K. Oh-I, T. Kezuka, J. I. Sakai, and H. Goto, "Comparison of patients with ocular tuberculosis in the 1990s and the 2000s," Japanese Journal of Ophthalmology, vol. 54, no. 1, pp. 19-23, 2010.

[17] C. C. Wykoff, M. B. Parrott, H. W. Flynn Jr., W. Shi, D. Miller, and E. C. Alfonso, "Nosocomial acute-onset postoperative endophthalmitis at a university teaching hospital (20022009)," American Journal of Ophthalmology, vol. 150, no. 3, pp. 392-398.e2, 2010.

[18] J. M. Moreau, L. L. Conerly, E. B. H. Hume et al., "Effectiveness of mupirocin and polymyxin B in experimental Staphylococcus aureus, Pseudomonas aeruginosa, and Serratia marcescens keratitis," Cornea, vol. 21, no. 8, pp. 807-811, 2002.

[19] P. C. Hessburg, J. P. Truant, and W. P. Penn, "Pseudomonas infections of the cornea in rabbits: an in vivo comparison of polymixin B and colistin sulfate," in Proceedings of the 2nd Interscience Conference on Antimicrobial Agents and Chemotherapy, J. C. Sylvester, Ed., pp. 131-139, American Society for Microbiology, Chicago, Ill, USA, OctoberNovember 1962.

[20] L. A. Wilson, "Chelation in experimental Pseudomonas keratitis," British Journal of Ophthalmology, vol. 54, no. 9, pp. 587-593, 1970.

[21] W. P. Penn, J. P. Truant, and P. C. Hessburg, "Evaluation of colistin sulfate and the sulfonamides in the in vitro and in vivo treatment of Pseudomonas corneal ulcers," Antimicrobial Agents and Chemotherapy, vol. 161, pp. 411-419, 1963.

[22] E. Kessler, B. J. Mondino, and S. I. Brown, "The corneal response to Pseudomonas aeruginosa: histopathological and enzymatic characterization," Investigative Ophthalmology \& Visual Science, vol. 16, no. 2, pp. 116-125, 1977.

[23] J. A. Hobden, L. S. Engel, M. C. Callegan, J. M. Hill, B. M. Gebhardt, and R. J. O'Callaghan, "Pseudomonas aeruginosa keratitis in leukopenic rabbits," Current Eye Research, vol. 12, no. 5, pp. 461-467, 1993.

[24] B. H. Iglewski, R. P. Burns, and I. K. Gipson, "Pathogenesis of corneal damage from Pseudomonas exotoxin A," Investigative Ophthalmology \& Visual Science, vol. 16, no. 1, pp. 73-76, 1977.

[25] B. A. Thibodeaux, A. R. Caballero, M. E. Marquart, J. Tommassen, and R. J. O'Callaghan, "Corneal virulence of Pseudomonas aeruginosa elastase $\mathrm{B}$ and alkaline protease produced by Pseudomonas putida," Current Eye Research, vol. 32, no. 4, pp. 373-386, 2007.

[26] M. R. Sawusch, T. P. O’Brien, J. D. Dick, and J. D. Gottsch, "Use of collagen corneal shields in the treatment of bacterial keratitis," American Journal of Ophthalmology, vol. 106, no. 3, pp. 279-281, 1988.

[27] H. Moreira, P. J. McDonnell, A. P. Fasano, D. L. Silverman, T. D. Coates, and A. Sevanian, "Treatment of experimental Pseudomonas keratitis with cyclo-oxygenase and lipoxygenase inhibitors," Ophthalmology, vol. 98, no. 11, pp. 16931697, 1991. 
[28] T. E. Clinch, J. A. Hobden, J. M. Hill, R. J. O'Callaghan, L. S. Engel, and H. E. Kaufman, "Collagen shields containing tobramycin for sustained therapy (24 hours) of experimental Pseudomonas keratitis," CLAO Journal, vol. 18, no. 4, pp. 245 247, 1992.

[29] D. S. Rootman and M. Krajden, "Continuous flow perfusion of gentamicin with a scleral shell reduces bacterial colony counts in experimental Pseudomonas keratitis," Journal of Ocular Pharmacology, vol. 9, no. 3, pp. 271-276, 1993.

[30] L. S. Engel, M. C. Callegan, J. M. Hill, A. T. Folkens, Y. Shimomura, and R. J. O'Callaghan, “The effectiveness of two ciprofloxacin formulations for experimental Pseudomonas and Staphylococcus keratitis," Japanese Journal of Ophthalmology, vol. 40, no. 2, pp. 212-219, 1996.

[31] S. Nos-Barbera, M. Portoles, A. Morilla, J. Ubach, D. Andreu, and C. A. Paterson, "Effect of hybrid peptides of cecropin a and melittin in an experimental model of bacterial keratitis," Cornea, vol. 16, no. 1, pp. 101-106, 1997.

[32] R. P. Kowalski, E. G. Romanowski, K. A. Yates, and Y. J. Gordon, "Lomefloxacin is an effective treatment of experimental bacterial keratitis," Cornea, vol. 20, no. 3, pp. 306-308, 2001.

[33] I. S. Barequet, P. Denton, G. J. Osterhout, S. Tuli, and T. P. O'Brien, "Treatment of experimental bacterial keratitis with topical trovafloxacin," Archives of Ophthalmology, vol. 122, no. 1, pp. 65-69, 2004.

[34] E. Aliprandis, J. Ciralsky, H. Lai, I. Herling, and H. R. Katz, "Comparative efficacy of topical moxifloxacin versus ciprofloxacin and vancomycin in the treatment of $P$. aeruginosa and ciprofloxacin-resistant MRSA keratitis in rabbits," Cornea, vol. 24, no. 2, pp. 201-205, 2005.

[35] J. Frucht-Pery, F. Raiskup, H. Mechoulam, M. Shapiro, E. Eljarrat-Binstock, and A. Domb, "Iontophoretic treatment of experimental Pseudomonas keratitis in rabbit eyes using gentamicin-loaded hydrogels," Cornea, vol. 25, no. 10, pp. 1182-1186, 2006.

[36] P. Bu, P. S. Riske, N. E. Zaya, R. Carey, and C. S. Bouchard, "A comparison of topical chlorhexidine, ciprofloxacin, and fortified tobramycin/cefazolin in rabbit models of Staphylococcus and Pseudomonas keratitis," Journal of Ocular Pharmacology and Therapeutics, vol. 23, no. 3, pp. 213-220, 2007.

[37] F. S. Mah, E. G. Romanowski, R. P. Kowalski, K. A. Yates, and Y. J. Gordon, "Zymar (gatifloxacin 0.3\%) shows excellent gram-negative activity against Serratia marcescens and Pseudomonas aeruginosa in a New Zealand white rabbit keratitis model," Cornea, vol. 26, no. 5, pp. 585-588, 2007.

[38] Y. Onlen, C. Tamer, H. Oksuz, N. Duran, M. E. Altug, and S. Yakan, "Comparative trial of different anti-bacterial combinations with propolis and ciprofloxacin on Pseudomonas keratitis in rabbits," Microbiological Research, vol. 162, no. 1, pp. 62-68, 2007.

[39] C. McCormick, A. Caballero, A. Tang, C. Balzli, J. Song, and R. O'Callaghan, "Effectiveness of a new tobramycin $(0.3 \%)$ and dexamethasone $(0.05 \%)$ formulation in the treatment of experimental Pseudomonas keratitis," Current Medical Research and Opinion, vol. 24, no. 6, pp. 1569-1575, 2008.

[40] D. Sensoy, E. Cevher, A. Sarici, M. Yilmaz, A. Özdamar, and N. Bergişadi, "Bioadhesive sulfacetamide sodium microspheres: evaluation of their effectiveness in the treatment of bacterial keratitis caused by Staphylococcus aureus and Pseudomonas aeruginosa in a rabbit model," European Journal of Pharmaceutics and Biopharmaceutics, vol. 72, no. 3, pp. 487-495, 2009.

[41] R. P. Kowalski, E. G. Romanowski, F. S. Mah, R. M. Q. Shanks, and Y. J. Gordon, "Topical levofloxacin 1.5\% overcomes in vitro resistance in rabbit keratitis models," Acta Ophthalmologica, vol. 88, no. 4, pp. e120-e125, 2010.

[42] E. Stangogiannis-Druya, C. Stangogiannis-Druya, R. Naranjo-Tackman, V. Vanzzini, and J. Villar-Kurí, "Bacterial corneal ulcer treated with intrastromal antibiotic. Experimental model in vivo," Archivos de la Sociedad Espanola de Oftalmologia, vol. 84, no. 3, pp. 123-132, 2009.

[43] W. K. Blaylock, B. Y. J. T. Yue, and J. B. Robin, "The use of concanavalin A to competitively inhibit Pseudomonas aeruginosa adherence to rabbit corneal epithelium," CLAO Journal, vol. 16, no. 3, pp. 223-227, 1990.

[44] J. Frucht-Pery, G. Golan, I. Hemo, H. Zauberman, and M. Shapiro, "Efficacy of topical gentamicin treatment after 193-nm photorefractive keratectomy in an experimental Pseudomonas keratitis model," Graefe's Archive for Clinical and Experimental Ophthalmology, vol. 233, no. 8, pp. 532534, 1995.

[45] M. J. Mannis, "The use of antimicrobial peptides in ophthalmology: an experimental study in corneal preservation and the management of bacterial keratitis," Transactions of the American Ophthalmological Society, vol. 100, pp. 243-271, 2002.

[46] K. Michalová, A. L. Moyes, S. Cameron et al., "Povidoneiodine (betadine) in the treatment of experimental Pseudomonas aeruginosa keratitis," Cornea, vol. 15, no. 5, pp. 533536, 1996.

[47] J. M. Koch, M. F. Refojo, L. A. Hanninen, F. L. Leong, and K. R. Kenyon, "Experimental Pseudomonas aeruginosa keratitis from extended wear of soft contact lenses," Archives of Ophthalmology, vol. 108, no. 10, pp. 1453-1459, 1990.

[48] E. B. Brockman, P. A. Tarantino, J. A. Hobden et al., "Keratotomy model of Pseudomonas keratitis: gentamicin chemotherapy," Refractive and Corneal Surgery, vol. 8, no. 1, pp. 39-43, 1992.

[49] C. A. Lawin-Brussel, M. F. Refojo, F. L. Leong, L. Hanninen, and K. R. Kenyon, "Effect of Pseudomonas aeruginosa concentration in experimental contact lens-related microbial keratitis," Cornea, vol. 12, no. 1, pp. 10-18, 1993.

[50] O. D. Solomon, H. Loff, B. Perla et al., "Testing hypotheses for risk factors for contact lens-associated infectious keratitis in an animal model," CLAO Journal, vol. 20, no. 2, pp. 109-113, 1994.

[51] M. I. Aswad, J. Baum, and M. Barza, "The effect of cleaning and disinfection of soft contact lenses on corneal infectivity in an animal model," American Journal of Ophthalmology, vol. 119, no. 6, pp. 738-743, 1995.

[52] A. S. Kreger, D. M. Lyerly, L. D. Hazlett, and R. S. Berk, "Immunization against experimental Pseudomonas aeruginosa and Serratia marcescens keratitis. Vaccination with lipopolysaccharide endotoxins and proteases," Investigative Ophthalmology \& Visual Science, vol. 27, no. 6, pp. 932-939, 1986.

[53] M. P. Holzer, H. P. Sandoval, L. G. Vargas et al., "Corneal flap complications in refractive surgery: part 2: postoperative treatments of diffuse lamellar keratitis in an experimental animal model," Journal of Cataract and Refractive Surgery, vol. 29, no. 4, pp. 803-807, 2003.

[54] M. P. Holzer, K. D. Solomon, D. T. Vroman et al., "Diffuse lamellar keratitis: evaluation of etiology, histopathologic findings, and clinical implications in an experimental animal model," Journal of Cataract and Refractive Surgery, vol. 29, no. 3, pp. 542-549, 2003.

[55] M. P. Holzer, L. G. Vargas, H. P. Sandoval et al., "Corneal flap complications in refractive surgery part 1: development 
of an experimental animal model," Journal of Cataract and Refractive Surgery, vol. 29, no. 4, pp. 795-802, 2003.

[56] M. P. Holzer, H. P. Sandoval, L. G. Vargas et al., "Evaluation of preoperative and postoperative prophylactic regimens for prevention and treatment of diffuse lamellar keratitis," Journal of Cataract and Refractive Surgery, vol. 30, no. 1, pp. 195-199, 2004.

[57] B. A. Schlech, J. D. Hansard, and F. C. Bach, "Effectiveness of neomycin and polymyxin ointments: prevention of Staphylococcus aureus keratitis in rabbits," Annals of Ophthalmology, vol. 7, no. 7, pp. 967-977, 1975.

[58] A. Kupferman and H. M. Leibowitz, "Quantitation of bacterial infection and antibiotic effect in the cornea," Archives of Ophthalmology, vol. 94, no. 11, pp. 1981-1984, 1976.

[59] A. Kupferman and H. M. Leibowitz, "Topical antibiotic therapy of Staphylococcal keratitis," Archives of Ophthalmology, vol. 95, no. 9, pp. 1634-1637, 1977.

[60] M. C. Callegan, J. M. Hill, M. S. Insler, J. A. Hobden, and R. J. O'Callaghan, “Methicillin-resistant Staphylococcus aureus keratitis in the rabbit: therapy with ciprofloxacin, vancomycin and cefazolin," Current Eye Research, vol. 11, no. 11, pp. 1111-1119, 1992.

[61] M. C. Callegan, J. A. Hobden, J. M. Hill, M. S. Insler, and R. J. O'Callaghan, "Topical antibiotic therapy for the treatment of experimental Staphylococcus aureus keratitis," Investigative Ophthalmology \& Visual Science, vol. 33, no. 11, pp. 30173023, 1992.

[62] M. C. Callegan, L. S. Engel, J. M. Hill, and R. J. O’Callaghan, "Ciprofloxacin versus tobramycin for the treatment of staphylococcal keratitis," Investigative Ophthalmology \& Visual Science, vol. 35, no. 3, pp. 1033-1037, 1994.

[63] J. M. Moreau, L. C. Green, L. S. Engel, J. M. Hill, and R. J. O'Callaghan, "Effectiveness of ciprofloxacin-polystyrene sulfonate (PSS), ciprofloxacin and ofloxacin in a Staphylococcus keratitis model," Current Eye Research, vol. 17, no. 8, pp. 808812, 1998.

[64] E. B. H. Hume, J. M. Moreau, L. L. Conerly et al., "Clarithromycin for experimental Staphylococcus aureus keratitis," Current Eye Research, vol. 18, no. 5, pp. 358-362, 1999.

[65] J. J. Dajcs, E. B. H. Hume, J. M. Moreau, A. R. Caballero, B. M. Cannon, and R. J. O'Callaghan, "Lysostaphin treatment of methicillin-resistant Staphylococcus aureus keratitis in the rabbit," Investigative Ophthalmology \& Visual Science, vol. 41, no. 6, pp. 1432-1437, 2000.

[66] S. A. Melki, A. Safar, F. Yaghouti et al., "Effect of topical povidone-iodine versus topical ofloxacin on experimental Staphylococcus keratitis," Graefe's Archive for Clinical and Experimental Ophthalmology, vol. 238, no. 5, pp. 459-462, 2000.

[67] J. J. Dajcs, J. M. Moreau, D. W. Stroman et al., "The effectiveness of tobramycin and Ocuflox in a prophylaxis model of Staphylococcus keratitis," Current Eye Research, vol. 23, no. 1, pp. 60-63, 2001.

[68] J. J. Dajcs, J. M. Moreau, B. A. Thibodeaux et al., "Effectiveness of ciprofloxacin and ofloxacin in a prophylaxis model of Staphylococcus keratitis," Cornea, vol. 20, no. 8, pp. 878-880, 2001.

[69] J. J. Dajcs, B. A. Thibodeaux, D. O. Girgis, M. D. Shaffer, S. M. Delvisco, and R. J. O'Callaghan, "Immunity to lysostaphin and its therapeutic value for ocular MRSA infections in the rabbit," Investigative Ophthalmology \& Visual Science, vol. 43, no. 12, pp. 3712-3716, 2002.

[70] J. J. Dajcs, B. A. Thibodeaux, M. E. Marquart, D. O. Girgis, M. Traidej, and R. J. O'Callaghan, "Effectiveness of ciprofloxacin, levofloxacin, or moxifloxacin for treatment of experimental Staphylococcus aureus keratitis," Antimicrobial Agents and Chemotherapy, vol. 48, no. 6, pp. 1948-1952, 2004.

[71] H. Oguz, H. Ozbilge, E. Oguz, and T. Gurkan, "Effectiveness of topical taurolidine versus ciprofloxacin, ofloxacin, and fortified cefazolin in a rabbit Staphylococcus aureus keratitis model," Current Eye Research, vol. 30, no. 3, pp. 155-161, 2005.

[72] H. Oksuz, N. Duran, C. Tamer, M. Cetin, and S. Silici, "Effect of propolis in the treatment of experimental Staphylococcus aureus Keratitis in Rabbits," Ophthalmic Research, vol. 37, no. 6, pp. 328-334, 2005.

[73] E. G. Romanowski, F. S. Mah, K. A. Yates, R. P. Kowalski, and Y. J. Gordon, "The successful treatment of gatifloxacinresistant Staphylococcus aureus keratitis with Zymar (gatifloxacin $0.3 \%$ ) in a NZW rabbit model," American Journal of Ophthalmology, vol. 139, no. 5, pp. 867-877, 2005.

[74] N. Duran, A. Koc, H. Oksuz et al., "The protective role of topical propolis on experimental keratitis via nitric oxide levels in rabbits," Molecular and Cellular Biochemistry, vol. 281, no. 1-2, pp. 153-161, 2006.

[75] Y. Fukaya, A. Kurita, H. Tsuruga et al., "Antibiotic effects of WP-0405, a thermo-setting ofloxacin gel, on methicillinresistant Staphylococcus aureus keratitis in rabbits," Journal of Ocular Pharmacology and Therapeutics, vol. 22, no. 4, pp. 258-266, 2006.

[76] E. G. Romanowski, F. S. Mah, R. P. Kowalski, K. A. Yates, and Y. J. Gordon, "Benzalkonium chloride enhances the antibacterial efficacy of gatifloxacin in an experimental rabbit model of intrastromal keratitis," Journal of Ocular Pharmacology and Therapeutics, vol. 24, no. 4, pp. 380-384, 2008.

[77] T. Wada, T. Kida, T. Inoue, H. Tokushige, H. Naka, and H. Sakaki, "Immunomodulatory effect of gatifloxacin on mouse peritoneal macrophages in vitro and in models of endotoxininduced rat conjunctivitis and rabbit bacterial keratitis," Ophthalmic Research, vol. 40, no. 2, pp. 54-60, 2008.

[78] J. Wang, X. Li, L. Xiong, and N. Sun, "Different concentrations of clarithromycin ophthalmic gel for rabbits corneal ulcers induced by Staphylococcus aureus," Yan Ke Xue Bao, vol. 24, no. 1, pp. 18-22, 2008.

[79] H. Eguchi, H. Shiota, S. Oguro, and T. Kasama, "The inhibitory effect of vancomycin ointment on the manifestation of MRSA keratitis in rabbits," Journal of Infection and Chemotherapy, vol. 15, no. 5, pp. 279-283, 2009.

[80] C. C. McCormick, A. R. Caballero, C. L. Balzli, A. Tang, and R. J. O'Callaghan, "Chemical inhibition of alpha-toxin, a key corneal virulence factor of Staphylococcus aureus," Investigative Ophthalmology \& Visual Science, vol. 50, no. 6, pp. 2848-2854, 2009.

[81] M. E. Sanders, E. W. Norcross, Q. C. Moore, A. Shafiee, and M. E. Marquart, "Efficacy of besifloxacin in a rabbit model of methicillin-resistant Staphylococcus aureus keratitis," Cornea, vol. 28, no. 9, pp. 1055-1060, 2009.

[82] M. Saleh, F. Jehl, A. Dory et al., "Ocular penetration of topically applied linezolid in a rabbit model," Journal of Cataract and Refractive Surgery, vol. 36, no. 3, pp. 488-492, 2010.

[83] M. E. Sanders, Q. C. Moore, E. W. Norcross, A. Shafiee, and M. E. Marquart, "Efficacy of besifloxacin in an early treatment model of methicillin-resistant Staphylococcus aureus keratitis," Journal of Ocular Pharmacology and Therapeutics, vol. 26, no. 2, pp. 193-198, 2010. 
[84] J. M. Moreau, D. O. Girgis, E. B. H. Hume, J. J. Dajcs, M. S. Austin, and R. J. O'Callaghan, "Phospholipase $A_{2}$ in rabbit tears: a host defense against Staphylococcus aureus," Investigative Ophthalmology \& Visual Science, vol. 42, no. 10, pp. 2347-2354, 2001.

[85] D. O. Girgis, J. J. Dajcs, and R. J. O'Callaghan, "Phospholipase $\mathrm{A}_{2}$ activity in normal and Staphylococcus aureus-infected rabbit eyes," Investigative Ophthalmology \& Visual Science, vol. 44, no. 1, pp. 197-202, 2003.

[86] R. J. O'Callaghan, D. O. Girgis, J. J. Dajcs, and G. D. Sloop, "Host defense against bacterial keratitis," Ocular Immunology and Inflammation, vol. 11, no. 3, pp. 171-181, 2003.

[87] R. J. O’Callaghan, C. C. McCormick, A. R. Caballero, M. E. Marquart, H. P. Gatlin, and J. D. Fratkin, "Age-related differences in rabbits during experimental Staphylococcus aureus keratitis," Investigative Ophthalmology \& Visual Science, vol. 48, no. 11, pp. 5125-5131, 2007.

[88] M. C. Callegan, L. S. Engel, J. M. Hill, and R. J. O'Callaghan, "Corneal virulence of Staphylococcus aureus: roles of alphatoxin and protein A in pathogenesis," Infection and Immunity, vol. 62, no. 6, pp. 2478-2482, 1994.

[89] J. J. Dajcs, M. S. Austin, G. D. Sloop et al., "Corneal pathogenesis of Staphylococcus aureus strain Newman," Investigative Ophthalmology \& Visual Science, vol. 43, no. 4, pp. 11091115, 2002.

[90] J. J. Dajcs, B. A. Thibodeaux, D. O. Girgis, and R. J. O'Callaghan, "Corneal virulence of Staphylococcus aureus in an experimental model of keratitis," DNA and Cell Biology, vol. 21, no. 5-6, pp. 375-382, 2002.

[91] R. J. O’Callaghan, M. C. Callegan, J. M. Moreau et al., "Specific roles of alpha-toxin and beta-toxin during Staphylococcus aureus corneal infection," Infection and Immunity, vol. 65, no. 5, pp. 1571-1578, 1997.

[92] E. B. H. Hume, J. J. Dajcs, J. M. Moreau, and R. J. O'Callaghan, "Immunization with alpha-toxin toxoid protects the cornea against tissue damage during experimental Staphylococcus aureus keratitis," Infection and Immunity, vol. 68, no. 10, pp. 6052-6055, 2000.

[93] E. B. H. Hume, J. J. Dajcs, J. M. Moreau, G. D. Sloop, M. D. P. Willcox, and R. J. O'Callaghan, "Staphylococcus corneal virulence in a new topical model of Infection," Investigative Ophthalmology \& Visual Science, vol. 42, no. 12, pp. 29042908, 2001.

[94] P. Z. J. Wu, H. Zhu, F. Stapleton et al., "Effects of $\alpha$ toxin-deficient Staphylococcus aureus on the production of peripheral corneal ulceration in an animal model," Current Eye Research, vol. 30, no. 1, pp. 63-70, 2005.

[95] N. Cole, E. B. Hume, A. K. Vijay, P. Sankaridurg, N. Kumar, and M. D. Willcox, "In vivo performance of melimine as an antimicrobial coating for contact lenses in models of CLARE and CLPU," Investigative Ophthalmology \& Visual Science, vol. 51, no. 1, pp. 390-395, 2010.

[96] C. L. Balzli, C. C. McCormick, A. R. Caballero et al., "Fluoroquinolone therapy in a rabbit model of post-LASIK methicillin-resistant Staphylococcus aureus keratitis," Journal of Cataract and Refractive Surgery, vol. 34, no. 2, pp. 295-301, 2008.

[97] S. N. Rao, Y. C. Fong, J. Kampmeier, L. D. Labree, D. J. Tanzer, and P. J. McDonnell, "The effectiveness of a topical antibiotic irrigating solution in a model of staphylococcal keratitis after lamellar keratectomy," American Journal of Ophthalmology, vol. 130, no. 1, pp. 20-24, 2000.

[98] T. Tungsiripat, M. A. Sarayba, M. B. Kaufman et al., "Fluoroquinolone therapy in multiple-drug resistant staphylococcal keratitis after lamellar keratectomy in a rabbit model," American Journal of Ophthalmology, vol. 136, no. 1, pp. 7681, 2003.

[99] F. S. Mah, E. G. Romanowski, D. K. Dhaliwal, K. A. Yates, and Y. J. Gordon, "Role of topical fluoroquinolones on the pathogenesis of diffuse lamellar keratitis in experimental in vivo studies," Journal of Cataract and Refractive Surgery, vol. 32, no. 2, pp. 264-268, 2006.

[100] M. K. Johnson, J. A. Hobden, M. Hagenah, R. J. O'Callaghan, J. M. Hill, and S. Chen, "The role of pneumolysin in ocular infections with Streptococcus pneumoniae," Current Eye Research, vol. 9, no. 11, pp. 1107-1114, 1990.

[101] L. D. Hazlett, M. M. Moon, M. Strejc, and R. S. Berk, "Evidence for $\mathrm{N}$-acetylmannosamine as an ocular receptor for $P$. aeruginosa adherence to scarified cornea," Investigative Ophthalmology \& Visual Science, vol. 28, no. 12, pp. 19781985, 1987.

[102] J. R. Gerke and M. V. Magliocco, "Experimental Pseudomonas aeruginosa infection of the mouse cornea," Infection and Immunity, vol. 3, pp. 209-216, 1971.

[103] J. R. Gerke and J. S. Nelson, "Oral vaccination and multivalent vaccine against Pseudomonas aeruginosa keratitis," Investigative Ophthalmology \& Visual Science, vol. 16, no. 1, pp. 76-80, 1977.

[104] E. Jackson and F. W. Hartman, "Experimental Bacillus pyocyaneus keratitis," The Journal of Laboratory and Clinical Medicine, vol. 12, no. 5, pp. 442-450, 1927.

[105] K. Kawaharajo and J. Y. Homma, "Synergistic effect of immune gamma-globulin fraction on protection by antibiotic against corneal ulcers in experimental mice infected with Pseudomonas aeruginosa," The Japanese Journal of Experimental Medicine, vol. 46, no. 3, pp. 155-165, 1976.

[106] Y. Hirao and J. Y. Homma, "Therapeutic effect of immunization with OEP, protease toxoid and elastase toxoid corneal ulcers in mice due to Pseudomonas aeruginosa infection," Japanese Journal of Experimental Medicine, vol. 48, no. 1, pp. 41-51, 1978.

[107] M. M. Moon, L. D. Hazlett, R. E. W. Hancock, R. S. Berk, and R. Barrett, "Monoclonal antibodies provide protection against ocular Pseudomonas aeruginosa infection," Investigative Ophthalmology \& Visual Science, vol. 29, no. 8, pp. 12771284, 1988.

[108] T. S. Zaidi, G. P. Priebe, and G. B. Pier, "A live-attenuated Pseudomonas aeruginosa vaccine elicits outer membrane protein-specific active and passive protection against corneal infection," Infection and Immunity, vol. 74, no. 2, pp. 975983, 2006.

[109] Y. Tanaka, "Effects of habekacin, a novel aminoglycoside antibiotic, on experimental corneal ulceration due to Pseudomonas aeruginosa," Journal of Antibiotics, vol. 34, no. 7, pp. 892-898, 1981.

[110] E. J. Lee, T. N. Truong, M. N. Mendoza, and S. M. J. Fleiszig, "A comparison of invasive and cytotoxic Pseudomonas aeruginosa strain-induced corneal disease responses to therapeutics," Current Eye Research, vol. 27, no. 5, pp. 289299, 2003.

[111] P. Karicherla, S. Aras, A. Aiyar, and J. A. Hobden, "Nona-Darginine amide suppresses corneal cytokines in Pseudomonas aeruginosa keratitis," Cornea, vol. 29, no. 11, pp. 1308-1314, 2010.

[112] P. Karicherla and J. A. Hobden, "Nona-D-arginine amide for prophylaxis and treatment of experimental Pseudomonas aeruginosa keratitis," Current Eye Research, vol. 35, no. 3, pp. 220-224, 2010. 
[113] A. Kumar, L. D. Hazlett, and F.-S. X. Yu, "Flagellin suppresses the inflammatory response and enhances bacterial clearance in a murine model of Peudomonas aeruginosa keratitis," Infection and Immunity, vol. 76, no. 1, pp. 89-96, 2008.

[114] M. S. F. Kwong, D. J. Evans, M. Ni, B. A. Cowell, and S. M. J. Fleiszig, "Human tear fluid protects against Pseudomonas aeruginosa keratitis in a murine experimental model," Infection and Immunity, vol. 75, no. 5, pp. 2325-2332, 2007.

[115] A. Thakur, R. P. Barrett, J. A. Hobden, and L. D. Hazlett, "Caspase-1 inhibitor reduces severity of Pseudomonas aeruginosa keratitis in mice," Investigative Ophthalmology \& Visual Science, vol. 45, no. 9, pp. 3177-3184, 2004.

[116] X. Huang, R. P. Barrett, S. A. McClellan, and L. D. Hazlett, "Silencing Toll-like receptor-9 in Pseudomonas aeruginosa keratitis," Investigative Ophthalmology \& Visual Science, vol. 46, no. 11, pp. 4209-4216, 2005.

[117] M. Wu, S. A. McClellan, R. P. Barrett, and L. D. Hazlett, " $\beta$-defensin-2 promotes resistance against infection with $P$. aeruginosa," Journal of Immunology, vol. 182, no. 3, pp. 16091616, 2009.

[118] E. B. H. Hume, N. Cole, L. L. Garthwaite, S. Khan, and M. D. P. Willcox, "A protective role for IL-6 in staphylococcal microbial keratitis," Investigative Ophthalmology \& Visual Science, vol. 47, no. 11, pp. 4926-4930, 2006.

[119] L. D. Hazlett, S. A. McClellan, R. P. Barrett, J. Liu, Y. Zhang, and S. Lighvani, "Spantide I decreases type I cytokines, enhances IL-10, and reduces corneal perforation in susceptible mice after Pseudomonas aeruginosa infection," Investigative Ophthalmology \& Visual Science, vol. 48, no. 2, pp. 797-807, 2007.

[120] M. L. Xue, A. Thakur, N. Cole et al., "A critical role for CCL2 and CCL3 chemokines in the regulation of polymorphonuclear neutrophils recruitment during corneal infection in mice," Immunology and Cell Biology, vol. 85, no. 7, pp. 525-531, 2007.

[121] T. Zaidi, M. Bajmoczi, T. Zaidi, D. E. Golan, and G. B. Pier, "Disruption of CFTR-dependent lipid rafts reduces bacterial levels and corneal disease in a murine model of Pseudomonas aeruginosa keratitis," Investigative Ophthalmology \& Visual Science, vol. 49, no. 3, pp. 1001-1009, 2008.

[122] T. Zaidi and G. B. Pier, "Prophylactic and therapeutic efficacy of a fully human immunoglobulin G1 monoclonal antibody to Pseudomonas aeruginosa alginate in murine keratitis infection," Infection and Immunity, vol. 76, no. 10, pp. 47204725, 2008.

[123] S. M. J. Fleiszig, T. S. Zaidi, E. L. Fletcher, M. J. Preston, and G. B. Pier, "Pseudomonas aeruginosa invades corneal epithelial cells during experimental infection," Infection and Immunity, vol. 62, no. 8, pp. 3485-3493, 1994.

[124] S. M. J. Fleiszig, T. S. Zaidi, and G. B. Pier, "Pseudomonas aeruginosa invasion of and multiplication within corneal epithelial cells in vitro," Infection and Immunity, vol. 63, no. 10, pp. 4072-4077, 1995.

[125] E. J. Lee, B. A. Cowell, D. J. Evans, and S. M. J. Fleiszig, "Contribution of ExsA-regulated factors to corneal infection by cytotoxic and invasive Pseudomonas aeruginosa in a murine scarification model," Investigative Ophthalmology \& Visual Science, vol. 44, no. 9, pp. 3892-3898, 2003.

[126] E. J. Lee, D. J. Evans, and S. M. J. Fleiszig, "Role of Pseudomonas aeruginosa ExsA in penetration through corneal epithelium in a novel in vivo model," Investigative Ophthalmology \& Visual Science, vol. 44, no. 12, pp. 5220-5227, 2003.

[127] R. J. O'Callaghan, L. S. Engel, J. A. Hobden, M. C. Callegan, L. C. Green, and J. M. Hill, "Pseudomonas keratitis: the role of an uncharacterized exoprotein, protease IV, in corneal virulence," Investigative Ophthalmology \& Visual Science, vol. 37, no. 4, pp. 534-543, 1996.

[128] L. S. Engel, J. A. Hobden, J. M. Moreau, M. C. Callegan, J. M. Hill, and R. J. O'Callaghan, "Pseudomonas deficient in protease IV has significantly reduced corneal virulence," Investigative Ophthalmology \& Visual Science, vol. 38, no. 8, pp. 1535-1542, 1997.

[129] M. J. Preston, P. C. Seed, D. S. Toder et al., "Contribution of proteases and LasR to the virulence of Pseudomonas aeruginosa during corneal infections," Infection and Immunity, vol. 65, no. 8, pp. 3086-3090, 1997.

[130] J. A. Hobden, "Pseudomonas aeruginosa proteases and corneal virulence," DNA and Cell Biology, vol. 21, no. 5-6, pp. 391-396, 2002.

[131] L. D. Hazlett, D. D. Rosen, and R. S. Berk, "Pseudomonas eye infections in cyclophosphamide treated mice," Investigative Ophthalmology \& Visual Science, vol. 16, no. 7, pp. 649-652, 1977.

[132] L. D. Hazlett, M. Zucker, and R. S. Berk, "Distribution and kinetics of the inflammatory cell response to ocular challenge with Pseudomonas aeruginosa in susceptible versus resistant mice," Ophthalmic Research, vol. 24, no. 1, pp. 32-39, 1992.

[133] J. A. Hobden, S. A. Masinick, R. P. Barrett, and L. D. Hazlett, "Aged mice fail to upregulate ICAM-1 after Pseudomonas aeruginosa corneal infection," Investigative Ophthalmology \& Visual Science, vol. 36, no. 6, pp. 1107-1114, 1995.

[134] J. A. Hobden, S. A. Masinick, R. P. Barrett, and L. D. Hazlett, "Proinflammatory cytokine deficiency and pathogenesis of Pseudomonas aeruginosa keratitis in aged mice," Infection and Immunity, vol. 65, no. 7, pp. 2754-2758, 1997.

[135] K. A. Kernacki and R. S. Berk, "Characterization of arachidonic acid metabolism and the polymorphonuclear leukocyte response in mice infected intracorneally with Pseudomonas aeruginosa," Investigative Ophthalmology \& Visual Science, vol. 36, no. 1, pp. 16-23, 1995.

[136] K. A. Kernacki, R. P. Barrett, J. A. Hobden, and L. D. Hazlett, "Macrophage inflammatory protein-2 is a mediator of polymorphonuclear neutrophil influx in ocular bacterial infection," Journal of Immunology, vol. 164, no. 2, pp. 10371045, 2000.

[137] K. A. Kernacki, R. P. Barrett, S. A. McClellan, and L. D. Hazlett, "Aging and PMN response to P. aeruginosa infection," Investigative Ophthalmology \& Visual Science, vol. 41, no. 10, pp. 3019-3025, 2000.

[138] D. O. Girgis, G. D. Sloop, J. M. Reed, and R. J. O'Callaghan, "A new topical model of Staphylococcus corneal infection in the mouse," Investigative Ophthalmology \& Visual Science, vol. 44, no. 4, pp. 1591-1597, 2003.

[139] D. O. Girgis, G. D. Sloop, J. M. Reed, and R. J. O'Callaghan, "Susceptibility of aged mice to Staphylococcus aureus keratitis," Current Eye Research, vol. 29, no. 4-5, pp. 269-275, 2004.

[140] D. O. Girgis, G. D. Sloop, J. M. Reed, and R. J. O'Callaghan, "Effects of toxin production in a murine model of Staphylococcus aureus keratitis," Investigative Ophthalmology \& Visual Science, vol. 46, no. 6, pp. 2064-2070, 2005.

[141] E. B. H. Hume, N. Cole, S. Khan et al., "A Staphylococcus aureus mouse keratitis topical infection model: cytokine balance in different strains of mice," Immunology and Cell Biology, vol. 83, no. 3, pp. 294-300, 2005.

[142] Y. Sun, A. G. Hise, C. M. Kalsow, and E. Pearlman, "Staphylococcus aureus-induced corneal inflammation is dependent on toll-like receptor 2 and myeloid differentiation factor 88 ," Infection and Immunity, vol. 74, no. 9, pp. 5325-5332, 2006. 
[143] N. Cole, M. Krockenberger, F. Stapleton et al., "Experimental Pseudomonas aeruginosa keratitis in interleukin-10 gene knockout mice," Infection and Immunity, vol. 71, no. 3, pp. 1328-1336, 2003.

[144] N. Cole, E. B. Hume, S. Khan et al., "The corneal response to infection with Staphylococcus aureus in the absence of interleukin-4," Immunology and Cell Biology, vol. 85, no. 4, pp. 333-337, 2007.

[145] E. B. H. Hume, N. Cole, L. L. Garthwaite, S. Khan, and M. D. P. Willcox, "A protective role for IL-6 in staphylococcal microbial keratitis," Investigative Ophthalmology \& Visual Science, vol. 47, no. 11, pp. 4926-4930, 2006.

[146] S. Khan, N. Cole, E. B. Hume et al., "The role of CXC chemokine receptor 2 in Pseudomonas aeruginosa corneal infection," Journal of Leukocyte Biology, vol. 81, no. 1, pp. 315-318, 2007.

[147] X. Huang, W. Du, S. A. McClellan, R. P. Barrett, and L. D. Hazlett, "TLR4 is required for host resistance in Pseudomonas aeruginosa keratitis," Investigative Ophthalmology \& Visual Science, vol. 47, no. 11, pp. 4910-4916, 2006.

[148] T. S. Zaidi, T. Zaidi, and G. B. Pier, "Role of neutrophils, MyD88-mediated neutrophil recruitment, and complement in antibody-mediated defense against Pseudomonas aeruginosa keratitis," Investigative Ophthalmology \& Visual Science, vol. 51, no. 4, pp. 2085-2093, 2010.

[149] A. Thakur, R. P. Barrett, S. McClellan, and L. D. Hazlett, "Regulation of Pseudomonas aeruginosa corneal infection in IL- $1 \beta$ converting enzyme (ICE, caspase-1) deficient mice," Current Eye Research, vol. 29, no. 4-5, pp. 225-233, 2004.

[150] S. A. McClellan, X. Huang, R. P. Barrett et al., "Matrix metalloproteinase- 9 amplifies the immune response to Pseudomonas aeruginosa corneal infection," Investigative Ophthalmology \& Visual Science, vol. 47, no. 1, pp. 256-264, 2006.

[151] Z. Zhou, M. Wu, R. P. Barrett, S. A. McClellan, Y. Zhang, and L. D. Hazlett, "Role of the Fas pathway in Pseudomonas aeruginosa keratitis," Investigative Ophthalmology \& Visual Science, vol. 51, no. 5, pp. 2537-2547, 2010.

[152] Y. Sun, M. Karmakar, S. Roy et al., "TLR4 and TLR5 on corneal macrophages regulate Pseudomonas aeruginosa keratitis by signaling through MyD88-dependent and independent pathways," Journal of Immunology, vol. 185, no. 7, pp. 4272-4283, 2010.

[153] M. Gadjeva, J. Nagashima, T. Zaidi, R. A. Mitchell, and G. B. Pier, "Inhibition of macrophage migration inhibitory factor ameliorates ocular Pseudomonas aeruginosa-induced keratitis," PLoS Pathogens, vol. 6, no. 3, Article ID e1000826, 2010.

[154] A. Ghosh, S. Lee, R. Dziarski, and S. Chakravarti, "A novel antimicrobial peptidoglycan recognition protein in the cornea," Investigative Ophthalmology \& Visual Science, vol. 50, no. 9, pp. 4185-4191, 2009.

[155] L. C. Huang, R. Y. Reins, R. L. Gallo, and A. M. McDermott, "Cathelicidin-deficient $\left(\mathrm{Cnlp}^{-1-}\right)$ mice show increased susceptibility to Pseudomonas aeruginosa keratitis," Investigative Ophthalmology \& Visual Science, vol. 48, no. 10, pp. 4498 4508, 2007.

[156] S. D. Davis and J. W. Chandler, "Experimental keratitis due to Pseudomonas aeruginosa: model for evaluation of antimicrobial drugs," Antimicrobial Agents and Chemotherapy, vol. 8, no. 3, pp. 350-355, 1975.

[157] S. D. Davis, L. D. Sarff, and R. A. Hyndiuk, "Staphylococcal keratitis. Experimental model in guinea pigs," Archives of Ophthalmology, vol. 96, no. 11, pp. 2114-2116, 1978.
[158] S. D. Davis, L. D. Sarff, and R. A. Hyndiuk, "Comparison of therapeutic routes in experimental Pseudomonas keratitis," American Journal of Ophthalmology, vol. 87, no. 5, pp. 710716, 1979.

[159] S. D. Davis, L. D. Sarff, and R. A. Hyndiuk, "Relative efficay of the topical use of amikacin, gentamicin and tobramycin in experimental Pseudomonas keratitis," Canadian Journal of Ophthalmology, vol. 15, no. 1, pp. 28-29, 1980.

[160] C. Ohadi, K. L. Litwin, H. Moreira et al., "Anti-inflammatory therapy and outcome in a guinea pig model of Pseudomonas keratitis," Cornea, vol. 11, no. 5, pp. 398-403, 1992.

[161] A. K. Vijay, P. Sankaridurg, H. Zhu, and M. D. Willcox, "Guinea pig models of acute keratitis responses," Cornea, vol. 28, no. 10, pp. 1153-1159, 2009.

[162] J. D. Choo, B. A. Holden, E. B. Papas, and M. D. P. Willcox, "Adhesion of Pseudomonas aeruginosa to orthokeratology and alignment lenses," Optometry and Vision Science, vol. 86, no. 2, pp. 93-97, 2009.

[163] K. H. Dannelly, Y. Liu, and S. K. Ghosh, "Pseudomonas aeruginosa corneal infection affects cholinergic enzymes in rat lacrimal gland," Archives of Microbiology, vol. 177, no. 1, pp. 47-53, 2002.

[164] I. S. Barequet, Z. Habot-Wilner, N. Keller et al., "Effect of amniotic membrane transplantation on the healing of bacterial keratitis," Investigative Ophthalmology \& Visual Science, vol. 49, no. 1, pp. 163-167, 2008.

[165] E. A. Szliter, R. P. Barrett, M. M. Gabriel, Y. Zhang, and L. D. Hazlett, "Pseudomonas aeruginosa-induced inflammation in the rat extended-wear contact lens model," Eye and Contact Lens, vol. 32, no. 1, pp. 12-18, 2006.

[166] C. Tam, J. J. Mun, D. J. Evans, and S. M. Fleiszig, "The impact of inoculation parameters on the pathogenesis of contact lens-related infectious keratitis," Investigative Ophthalmology \& Visual Science, vol. 51, no. 6, pp. 3100-3106, 2010.

[167] W. Behrens-Baumann, H. -H. Paul, and R. Ansorg, "Treatment of Pseudomonas aeruginosa keratitis with tobramycin and gentamicin: an animal experimental study," Klinische Monatsblatter fur Augenheilkunde, vol. 178, no. 3, pp. 197199, 1981.

[168] P. R. Badenoch, G. J. Hay, P. J. McDonald, and D. J. Coster, "A rat model of bacterial keratitis. Effect of antibiotics and corticosteroid," Archives of Ophthalmology, vol. 103, no. 5, pp. 718-722, 1985.

[169] P. R. Badenoch, P. J. McDonald, and D. J. Coster, "Effect of inflammation on antibiotic penetration into the anterior segment of the rat eye," Investigative Ophthalmology \& Visual Science, vol. 27, no. 6, pp. 958-965, 1986.

[170] S. S. Twining, X. Zhou, D. P. Schulte, P. M. Wilson, B. Fish, and J. Moulder, "Effect of vitamin A deficiency on the early response to experimental Pseudomonas keratitis," Investigative Ophthalmology \& Visual Science, vol. 37, no. 4, pp. 511-522, 1996.

[171] S. Hayes, C. Boote, J. Lewis et al., "Comparative study of fibrillar collagen arrangement in the corneas of primates and other mammals," Anatomical Record, vol. 290, no. 12, pp. 1542-1550, 2007.

[172] J. T. Henriksson, A. M. McDermott, and J. P. Bergmanson, "Dimensions and morphology of the cornea in three strains of mice," Investigative Ophthalmology \& Visual Science, vol. 50, no. 8, pp. 3648-3654, 2009.

[173] J. V. Jester, A. Budge, S. Fisher, and J. Huang, "Corneal keratocytes: phenotypic and species differences in abundant protein expression and in vitro light-scattering," Investigative 
Ophthalmology \& Visual Science, vol. 46, no. 7, pp. 23692378, 2005.

[174] J. L. Ojeda, J. A. Ventosa, and S. Piedra, "The threedimensional microanatomy of the rabbit and human cornea. A chemical and mechanical microdissection-SEM approach," Journal of Anatomy, vol. 199, no. 5, pp. 567-576, 2001.

[175] S. Hayashi, T. Osawa, and K. Tohyama, "Comparative observations on corneas, with special reference to Bowman's layer and Descemet's membrane in mammals and amphibians," Journal of Morphology, vol. 254, no. 3, pp. 247-258, 2002.

[176] M. Reichard, M. Hovakimyan, A. Wree et al., "Comparative in vivo confocal microscopical study of the cornea anatomy of different laboratory animals," Current Eye Research, vol. 35, no. 12, pp. 1072-1080, 2010.

[177] J. E. Schechter, D. W. Warren, and A. K. Mircheff, "A lacrimal gland is a lacrimal gland, but rodent's and rabbit's are not human," Ocular Surface, vol. 8, no. 3, pp. 111-134, 2010.

[178] L. Royle, E. Matthews, A. Corfield et al., "Glycan structures of ocular surface mucins in man, rabbit and dog display species differences," Glycoconjugate Journal, vol. 25, no. 8, pp. 763773, 2008. 


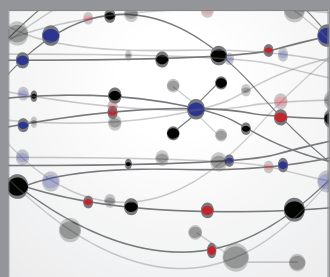

The Scientific World Journal
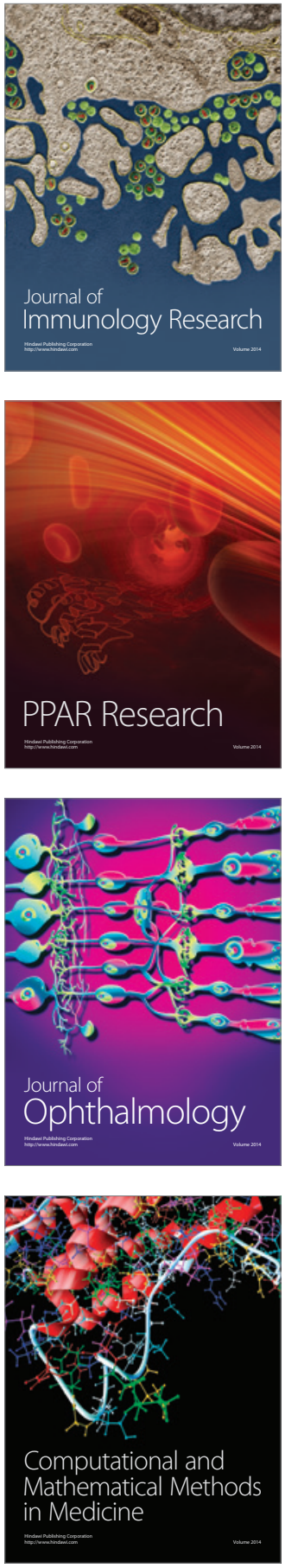

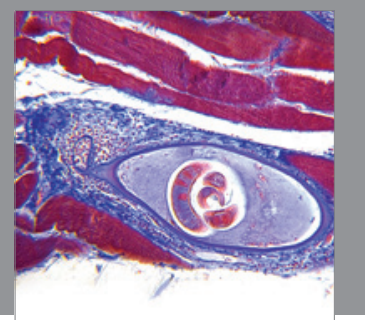

Gastroenterology

Research and Practice
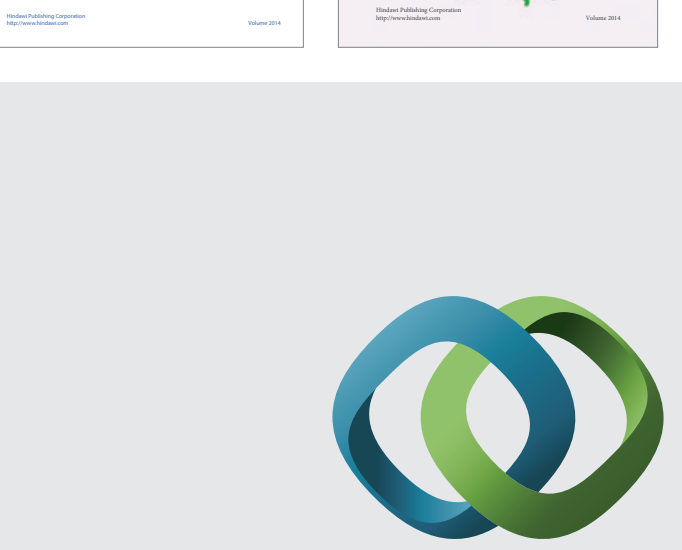

\section{Hindawi}

Submit your manuscripts at

http://www.hindawi.com
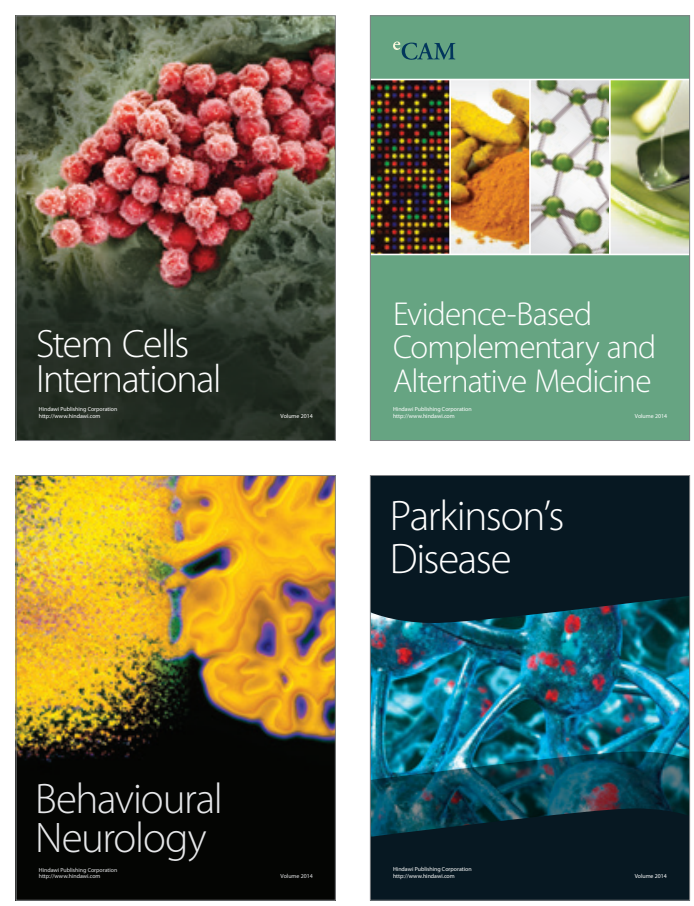

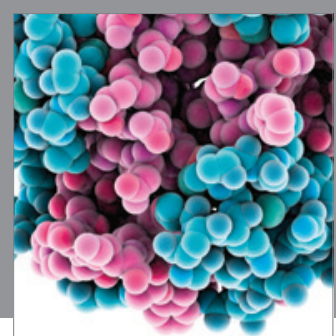

Journal of
Diabetes Research

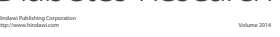

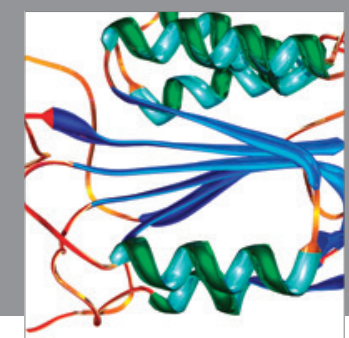

Disease Markers
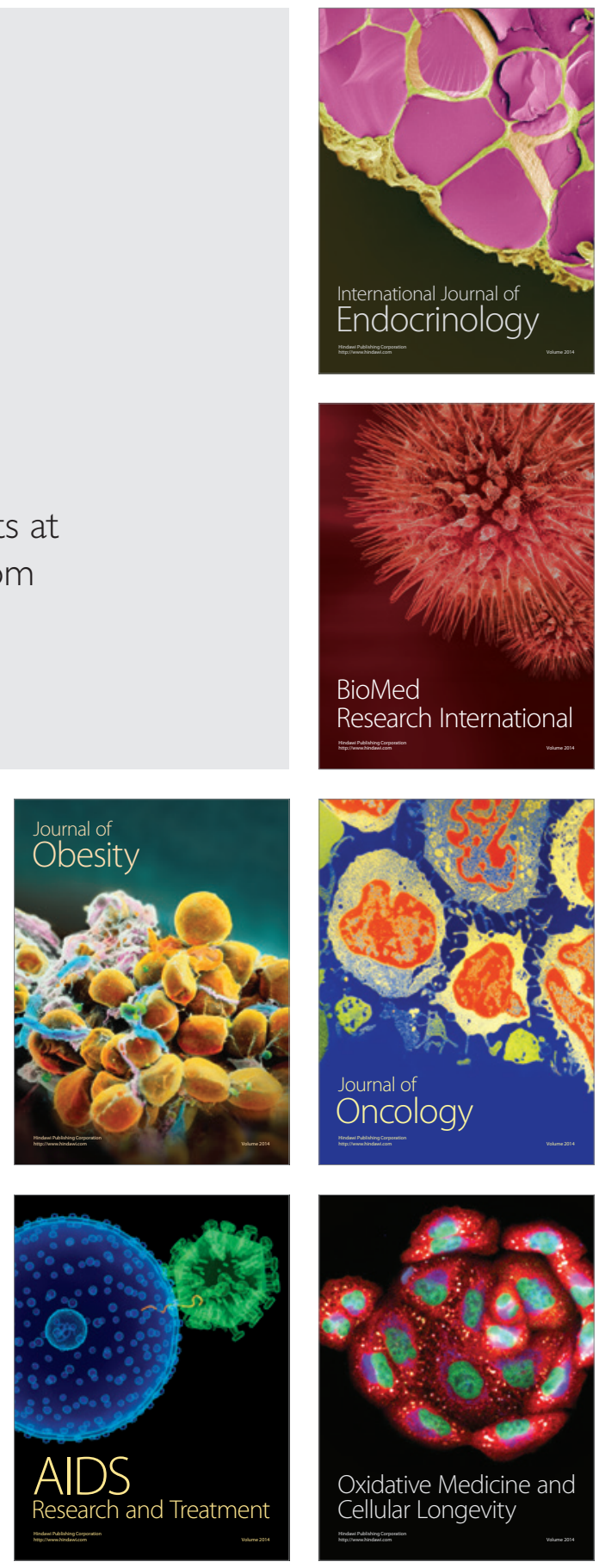